\title{
Sobre identidades, latinoamericanidades e construçáo de saberes em Terapia Ocupacional: diálogos com Boaventura de Sousa Santos ${ }^{1}$
}

\author{
Sandra Maria Galheigo \\ Departamento de Fisioterapia, Fonoaudiologia e Terapia Ocupacional, \\ Faculdade de Medicina, Universidade de São Paulo - USP, São Paulo, SP, Brasil
}

\begin{abstract}
Resumo: Este ensaio realiza uma reflexão sobre a constituição da identidade e a produção de conhecimento no âmbito das discussões sobre Terapia Ocupacional na América Latina. O texto apresenta o processo reflexivo e subjetivo do autor ao discorrer sobre a temática central e dialogar com as ideias de Boaventura de Sousa Santos. Discorre, de forma sintética, sobre a produção acadêmica brasileira na temática Terapia Ocupacional, identidade e complexidade e o potencial interesse internacional sobre o tema. Aponta para as tensões da subjetividade contemporânea, que transita entre o individual e o coletivo, o universal e o singular, e seus desdobramentos para a constituição dos saberes e práticas da Terapia Ocupacional. Discute os impactos da demanda por produtividade na universidade contemporânea e reflete sobre as dificuldades dos pesquisadores frente às exigências acadêmico-administrativas cotidianas. Destaca as dificuldades do compartilhamento de saberes e experiências entre os terapeutas ocupacionais latino-americanos e questiona sobre a existência de uma identidade latino-americana, apontando as tensões que circunscrevem os possíveis consensos e diferenças.
\end{abstract}

Palavras-chave: Terapia Ocupacional/Tendências, Conhecimento, América Latina.

\section{Identities, latin american matters and knowledge production in Occupational Therapy: dialogues with Boaventura de Sousa Santos}

\begin{abstract}
This essay reflects on the constitution of identity and knowledge production within the realm of discussions about occupational therapy in Latin America. The text presents the reflective and subjective processes experienced by the author, while discussing the central theme and dialoguing with the ideas of Boaventura de Sousa Santos. It briefly describes the Brazilian academic production on the themes of occupational therapy, identity and complexity, and the potential international interests on the subject. It emphasizes the tensions of contemporary subjectivity which moves across the individual and the collective, the universal and the singular, and its consequences to the constitution of occupational therapy knowledge and practice. The essay discusses the impacts of the demands for productivity in contemporary university and stresses the researchers' difficulties regarding daily academic and administrative requirements. The paper highlights the difficulties of sharing knowledge and experiences among Latin American occupational therapists and questions the existence of a Latin American identity, drawing attention to the tensions that circumscribe possible consensus and differences.
\end{abstract}

Keywords: Occupational Therapy/Trends, Knowledge, Latin America.

Autor para correspondência: Sandra Maria Galheigo, Centro de Docência e Pesquisa em Terapia Ocupacional, Faculdade de Medicina Universidade de São Paulo, Rua Cipotânea, 51, Cidade Universitária, CEP 05360-160, São Paulo, SP, Brasil, e-mail: sandramg@usp.br Recebido em 26/7/2012; Revisão em 23/1/2013; Aceito em 18/2/2013. 


\section{Dedico este texto \\ às companheiras, guerreiras da causa. Não preciso nomeá-las, Elas se reconhecerão.}

O convite para participar na mesa-redonda As questóes da produção do conhecimento e da constituição das identidades na América Latina no XII Congresso Brasileiro e IX Congresso Latino-Americano de Terapia Ocupacional parecia desafiador. Afinal, falar sobre identidades e saberes é inicialmente um convite à divagaçáo. O que está explícito no pedido? O que jaz oculto? Por onde desenrolar o fio da meada? Enfrenta-se aí o primeiro embate com o tema. Uma exposição oral é preparada e realizada. Este artigo apresenta o conteúdo revisado e ampliado dessa exposição sob a forma de um artigo de reflexão.

\section{Primeiro ato}

Leio o título da mesa-redonda e busco compreender seu objetivo - a reflexão sobre as questóes da produção de conhecimento e... Interrompo a leitura. O pensamento vaga e associa livremente: produçáo de conhecimento e demanda por produtividade que vêm acontecendo em detrimento do fomento à criação e ao compartilhamento de ideias. Produção de conhecimento e sua transformação em produtos, em números. Impactos que não são legitimados pelas provocaçóes que suscitam, pelos encantamentos que provocam, pelas curiosidades que despertam. Impactos, ao contrário, medidos por fórmulas matemáticas que se resumem em índices $h$, calculados pelo volume de citaçôes. Produção que vira critério de avaliação, exigência para o direito de se produzir saber, de se fazer pesquisa, e de participar nos programas de pós-graduação do país.

Continuo com a leitura do título: e a constituiçáo das identidades na América Latina. Quais são os nexos? É melhor rever a proposição da mesa-redonda por inteiro: As questôes da produção do conhecimento e da constituiçấo das identidades na América Latina.

O que há por traz dessa associação que não se revela ao primeiro olhar, à divagação primeira? Uma primeira questão é sobre o que conecta as duas temáticas - conhecimento e identidades -, sobre as quais se pode refletir longamente de maneira isolada, distinta. A que autores recorrer? Que diálogos construir?

\section{Segundo ato}

Uma pilha de livros e Boaventura de Sousa Santos soam como um convite. Revisito capítulos e trechos. Reencontro com o já lido em algum momento e perdido em alguma gaveta da memória. Esboços de diálogos. Diálogos com Boaventura dos Santos.
Uma frase surge como uma primeira provocação para reflexão:

A questão da identidade é assim semifictícia e seminecessária. Para quem a formula, apresenta-se sempre como uma ficção necessária. Se a resposta é obtida, seu êxito mede-se pela intensidade da consciência de que a questão fora, desde o início, uma necessidade fictícia. É, pois, crucial conhecer quem pergunta pela identidade, em que condiçóes, contra quem, com que propósitos e com que resultados. (SANTOS, 1999, p. 135).

O texto começa a mostrar o seu fio, a ganhar forma. Inversões. Recomposições. É a meada ou o fio que surge primeiro? O começo vem em forma de síntese. A síntese antes das partes, do todo. Um título para o texto sem texto: Sobre identidades, latinoamericanidades e a construção de saberes em Terapia Ocupacional: Diálogos com Boaventura de Sousa Santos.

Com o título como guia, cabe novamente a pergunta: Por que discutir identidade? Por que nos perguntamos sobre nossa identidade profissional?

Questão semelhante foi discutida no Congresso Brasileiro de Terapia Ocupacional realizado em Águas de Lindóia, São Paulo, em 1999, em uma mesa-redonda intitulada: Identidade profissional e transdisciplinaridade: Tensôes no campo da Terapia Ocupacional.

Três apresentaçôes, três artigos: Identidade e complexidade (LIMA, 1999), Conversando sobre identidade profissional (FURTADO, 1999) e A transdisciplinaridade enquanto princípio e realidade das açôes de saúde (GALHEIGO, 1999). As três apresentaçóes se propuseram a falar sobre a identidade profissional do terapeuta ocupacional, tomando como referencial a perspectiva da complexidade e trazendo para o âmbito do debate os conceitos de interdisciplinaridade e transdisciplinaridade. 
As apresentaçóes ofereceram três qualificativos à identidade, diversos porém consonantes: identidade positiva, identidade complexa e identidade plural.

Eliane Furtado (1999, p. 47) debateu sobre a constituição de uma identidade positiva a partir da composiçáo da "[...] palavra ideo, do grego idéa, e positiva, do latim escolástico positivu." Assim, a autora associou idéa com o significado de princípio, aparência, e positivu com o sentido de evidente, efetivo, real. Produziu assim diálogos sobre uma identidade profissional positiva enquanto identidade evidente, efetiva, aparência real.

Elizabeth Lima (1999, p. 43), baseando-se em Edgar Morin, refletiu sobre a constituição de uma identidade processual, complexa, que pudesse "[...] abarcar a multiplicidade das problemáticas que habitam nosso campo [...]" e reportasse, ao mesmo tempo, a um "[...] sentido de pertinência a uma comunidade [...]". A autora concluiu propondo que entendamos a identidade do terapeuta ocupacional como uma identidade feita de diferenças, que se oponha à ideia de estabilidade da identidade-relógio e componha uma identidade-nuvem, de forma a enfatizar a possibilidade de novas configuraçóes e formatos profissionais.

Já a contribuição que fiz à discussão, também motivada pelos trabalhos de Morin, colocou a possibilidade de pensarmos a identidade do terapeuta ocupacional segundo a perspectiva de uma identidade plural, em oposição à ideia de uma identidade única, universal (GALHEIGO, 1999). Ao final, propus que, para vivermos com mais plenitude os desafios do mundo contemporâneo, devemos admitir a complexidade de nossas práticas, de nossas terapias ocupacionais, plurais, multirreferenciais.

Passaram-se 13 anos daquele congresso e cabe perguntar o que mudou deste entáo, no que mudamos em 13 anos e, inclusive, se, de fato, mudamos. Também refletir se a questão da identidade seria um tema brasileiro e latino-americano.

Boaventura de Sousa Santos (1999), discorrendo sobre a questão da cultura e os motivos que levaram os artistas latino-americanos e africanos, vivendo na Europa, a colocarem a si próprios a questão da identidade, lembra que os artistas europeus raramente tiveram de se perguntar sobre sua identidade.

Seguindo a linha de pensamento de Boaventura, me pergunto se aconteceria algo semelhante entre terapeutas ocupacionais latino-americanos e africanos. A proposição de discutir sobre a identidade nos congressos de Terapia Ocupacional de 1999 e 2011 é, em si mesma, desafiadora e nos remete à questáo de se nós, terapeutas ocupacionais do Sul, precisaríamos discutir com maior frequência sobre nossa identidade profissional para nos diferenciarmos da identidade incorporada no início da profissão, no bojo das bases teórico-práticas importadas dos países do Norte. Sentimos necessidade de afirmar uma identidade latino-americana, uma identidade do Sul, que garanta visibilidade ao que temos de singular?

\section{Terceiro ato}

Deixando as divagaçóes de lado e querendo saber o que tem sido produzido sobre o tema, busco o auxílio dos poderosos mecanismos de busca contemporâneos, inexistentes há 13 anos. Consulto a base de dados Scopus como um oráculo. Digito: terapia ocupacional AND identidade. Nenhum resultado. Digito: terapia ocupacional AND identidad. Nenhum resultado também. O significado da consulta é inquietante e nos leva a duas possíveis conclusóes: ou os terapeutas ocupacionais latino-americanos não produzem textos sobre identidade ou os periódicos latino-americanos estão sub-representados nas bases de dados internacionais. A segunda alternativa é a mais plausível e revela um primeiro resultado para discussão: a dificuldade de acesso a textos de Terapia Ocupacional de origem latina nas bases de dados internacionais.

Retorno ao Scopus e digito: occupational therapy AND identity, o que resulta em 174 produtos (conforme a nova semântica científico-industrial do momento).

Os artigos falam de identidade e Terapia Ocupacional, mas com sentidos variados: ser mãe com artrite (SMITH et al., 2011), o indivíduo após um traumatismo crânio-encefálico e sua nova identidade (HOOGERDIJK; RUNGE; HAUGBOELLE, 2011), se a Terapia Ocupacional é uma profissáo na adolescência (TURNER, 2011). Falam de identidade pessoal e de identidade profissional.

Tento novamente: occupational therapy AND identity, acrescentando AND Latin America. Os 174 resultados viram nenhum. A Terapia Ocupacional na América Latina e a Terapia Ocupacional internacional, expressa na língua inglesa, parecem não confluir.

Procuro na base de dados Scielo, em português e espanhol, e também não encontro resultados. Consulto a base Bireme, que oferece acesso ao LILACS, o mais importante índice da literatura científica e técnica em Saúde para a América Latina e Caribe e encontro nove resultados, dos quais apenas quatro remetem à discussão da identidade 
profissional, todos brasileiros: dois artigos já citados (LIMA, 1999; FURTADO, 1999) e mais dois que discutem o campo da Terapia Ocupacional e remetem indiretamente ao tema da identidade (MACHADO, 1991; MÂNGIA, 1998).

A pesquisa bibliográfica pouco revela e deixa em dúvida se a questão da identidade profissional da Terapia Ocupacional seria um tema latino-americano ou, prioritariamente, brasileiro. Mas como dialogar com os terapeutas ocupacionais latino-americanos? Onde os terapeutas ocupacionais latino-americanos, escritores de sua profissão, depositaram suas ideias? Prioritariamente em livros, teses, manuscritos apresentados em congressos, o que nos faz desejar melhores meios de compartilhamento do que tem sido produzido. Esse assunto daria uma pesquisa e mais alguns projetos de cooperação, mas o tempo é pouco. Minha fala se aproxima e tenho 15 minutos de debate. O tempo é curto. As pessoas engrossam os congressos, o que é bom, embora os tempos de apresentaçáo diminuam e, com isso, a possibilidade de discussōes e reflexôes mais aprofundadas. Mas não vamos perder tempo com a questão do tempo, porque não há tempo.

Volto ao Scopus e digito: occupational therapy AND professional identity, encontro 43 artigos. Começo a varredura manual e constato que terapeutas ocupacionais americanos, ingleses, australianos têm algum interesse em discutir a identidade profissional. Passo por títulos e resumos e gostaria de ler vários: Política e complexidade em um campo de trabalho intercultural: A experiência do Vietnam (WHITEFORD; McALLISTER, 2007); A profissionalização da Terapia Ocupacional: Um desafio contínuo (CLOUSTON; WHITCOMBE, 2008). Um deles ganha um destaque especial: Não peçam para que eu continue o mesmo: Foucault e as identidades profissionais dos terapeutas ocupacionais (MacKEY, 2007). Outro, ainda: Identidades pessoais e profissionais e o desenvolvimento da Terapia Ocupacional na América progressista (METAXAS, 2000). Não se trata da América Latina, entretanto.

Seria interessante estudar o tema da identidade profissional em algum momento. Faço notas e prometo lê-las mais tarde. Talvez uma revisão da literatura para saber o que os terapeutas ocupacionais nos vários países pensam sobre a identidade profissional! Mas quais terapeutas ocupacionais e de onde? Pergunto-me sobre como podemos discutir identidade profissional sem cairmos na armadilha da identidade universal, única, sem os contextos e sem o lugar, sem as histórias, os aromas e as cores. Esses são pontos que remetem ao debate universalismo versus contexto - outro tema contemporâneo.
Com a pesquisa nas bases de dados infrutífera, constato que preciso voltar à Boaventura dos Santos. Urgente. Mas a que horas? Os pareceres, as prestaçôes de conta da pesquisa, os documentos, as comissóes, as cansáveis e inúmeras reunióes. Onde foi parar a possibilidade de uma universidade das ideias, Boaventura? Por que fomos nos meter no meio das burocracias, dos papéis e seu carimbos?

Paro e me apronto para mais um dia de poucas criações. O texto se revolta. Ele começa a ganhar corpo e demanda nascer. A inquietude toma conta de meu corpo. Escrever em um corpo feminino é mantê-lo frequentemente grávido. Sinto as pontadas e pontapés de meus filhos na barriga em meio às falas e às conferências. Como antes, as ideias agora demandam vida; o texto reclama existência, autonomia e quer se separar de mim. Mas precisa ainda que eu o mantenha vivo. Se relegá-lo a segundo plano posso perder "o fio e as meadas".

Tomo notas para não esquecer. Quantas vezes não fiz o mesmo ao longo da minha trajetória de pesquisadora e estudante de pós-graduação? Anotaçóes enquanto os filhos brincam nos parquinhos, enquanto espero a saída da escola. Minha filha anotando minhas ideias enquanto eu cozinho a janta; meu filho desenhando no livro de Foucault enquanto tomo notas de suas ideias. Quantas outras colegas-pesquisadoras não fizeram o mesmo?

Não creio ser possível discutir a produção de conhecimento em uma profissão eminentemente feminina sem nos determos nas questóes de gênero e trabalho. Mas deve ser igualmente necessário refletir sobre os processos subjetivos e singulares que subjazem ao "ser sujeito" e ao "ser sujeitopesquisador". Necessitamos romper com o discurso produtivista e retomar o processo artesanal cotidiano, peculiar a cada sujeito, em sua tecelagem de ideias e palavras, levandoem conta, sem dúvida, os contextos sociais e políticos em que os estudos são produzidos.

\section{Quarto ato}

Outro dia. Retorno à Boaventura e aceito seu desafio de refletir sobre "[...] quem pergunta pela identidade, em que condiçóes, contra quem, com que propósitos e com que resultados." (SANTOS, 1999, p. 135). Outro fragmento de texto me leva além:

Sabemos hoje que as identidades culturais não são rígidas nem, muito menos, imutáveis. São resultados sempre transitórios e fugazes de processos de identificação. Mesmo as identidades aparentemente sólidas, como 
a de mulher, homem, país africano, país latino-americano ou país europeu, escondem negociaçóes de sentido, jogos de polissemia, choques de temporalidades em constante processo de transformação, responsáveis em última instância pela sucessão de configurações hermenêuticas que de época para época dão corpo e vida a tais identidades. Identidades são, pois, identificaçôes em curso. (SANTOS, 1999, p. 135).

Esse trecho nos convida a pensar sobre quais são as "identificaçôes em curso" dos terapeutas ocupacionais latino-americanos. Seria interessante conhecer o que nos alinha na construção do conhecimento e o que nos afasta. Afinal, como diz Boaventura, "[...] identificaçóes, além de plurais, são dominadas pela obsessão da diferença e pela hierarquia das distinçóes." (SANTOS, 1999, p. 135).

Enumero algumas questóes que gostaria de discutir com os participantes: Que "identificaçôes” temos produzido desde que a profissão foi criada no continente tendo como base o que já existia nos países anglo-saxóes? Quais resultam do fato de a Terapia Ocupacional ter surgido como profissão na América Latina quando o pós-guerra queria produzir alinhamentos políticos com a outra América? Em que nos une o fato de termos vivido períodos ditatoriais e, sofrida e coletivamente, construído emancipaçóes? Lutamos pela cidadania e buscamos estabelecer novos contratos sociais em nossos países em períodos de tempo próximos? Com os usuários de nossos serviços, das comunidades, grupos e movimentos, articulamos novos poderes contratuais? Os terapeutas ocupacionais latino-americanos concordariam que possuem essas identificaçóes em curso? Seriam apenas essas?

Compreendo que para responder a essas questóes há que se retomar que as tensóes que permeiam a assistência oferecida e o conhecimento profissional produzido estão também imbricadas nas múltiplas e tensas linhas de construção da subjetividade na modernidade. Santos (1999) destaca duas que conhecemos bem: a primeira é a tensão entre a subjetividade individual e a subjetividade coletiva; a segunda é sobre a concepção concreta e contextual da subjetividade versus a concepção abstrata, sem tempo nem espaços definidos.

Reconheço que a Terapia Ocupacional nos dias de hoje, bem como as idenficaçóes em curso que fazemos na América Latina, se alinha às tensões contemporâneas. Há terapeutas ocupacionais que desenvolvem seus trabalhos a partir de uma concepçáo individualizada e abstrata (universal) de subjetividade; isto é, adotando a perspectiva de que os problemas devem ser tratados como transtornos pessoais. Enquanto isso, outros baseiam sua prática em uma concepção coletiva de subjetividade, que se quer contextual - social, cultural, econômica, ecológica e política. Pode-se afirmar que esses dois movimentos fazem parte das nossas identificaçóes em curso; são tendências presentes na produção e reprodução do conhecimento da Terapia Ocupacional, pois transversais às questóes contemporâneas.

Defendo que os fatores históricos e políticos formam a base tanto das semelhanças como das diferenças que permeiam nossas práticas profissionais. Afinal, quando difundida para os países latinoamericanos, a profissáo surgiu com uma prática centrada na concepção de indivíduo, aquele que devia ser tratado, adaptado para ser independente. Uma prática centrada numa superação individual, de forma descontextualizada e a-histórica.

Gradualmente, mas principalmente nos anos 1980, as sociedades latino-americanas começaram a clamar por emancipação coletiva e a demandar direitos de cidadania e novos contratos sociais que pudessem deslocar o perfil regulador e excludente dos regimes políticos em curso. Terapeutas ocupacionais acompanharam essa trajetória e produziram práticas e saberes em consonância com os movimentos sociais e sua luta por acesso a saúde, educação, cultura, trabalho, seguridade e assistência social. A produção de conhecimento no âmbito da Terapia Ocupacional vem desde então acompanhando e dialogando com as necessidades e demandas de cuidado, participação e inclusão social das pessoas e coletivos. No processo tanto de conhecimento de suas atividades, cotidianos e histórias de vida como de composição de estratégias de cuidado, assistência e construção de redes de suporte, novas epistemologias passaram a ser produzidas não apenas na América Latina como nos países do Sul (GALHEIGO, 2011), o que poderíamos identificar com o que Boaventura nomeia de "epistemologias do sul":

Designamos a diversidade epistemológica do mundo por epistemologias do Sul. O Sul é aqui concebido metaforicamente como um campo de desafios epistêmicos, que procuram reparar os danos e impactos historicamente causados pelo capitalismo em sua relaçáo colonial com o mundo. Essa concepção do Sul sobrepóe-se em parte ao Sul geográfico, o conjunto de países e regióes do mundo que foram submetidos ao colonialismo europeu e que, com exceção da Austrália e da Nova Zelândia, não atingiram níveis de desenvolvimento semelhantes ao do Norte global (Europa e América do Norte). (SANTOS; MENESES, 2010, p. 19).

Assim, parto do pressuposto de que a produção de “epistemologias do sul” é a principal “identificação em curso" da Terapia Ocupacional latino-americana contemporânea. 


\section{Quinto ato}

Não é possível chegar ao fim sem voltar ao início. A sensaçáo primeira, o primeiro desconforto quando a discussão é sobre a produção de conhecimento no mundo acadêmico contemporâneo e nos deparamos com os impactos da adesão do Sul à perspectiva do publish or perish do Norte global. Não é possível falar de produçáo de conhecimento sem apontar as pressóes produtivistas e de desempenho exercidas por universidades, agências de fomento e agências reguladoras do ensino de pós-graduação no Brasil. Práticas que valorizam menos a construçáo de práticas e saberes e preocupam-se mais com os ranqueamentos em ISIs/Thompsons e Times Higher Education. O economicismo que reina nas universidades e as faz reféns de uma racionalidade fabril, empresarial, tem se tornado parte do dia a dia do trabalho universitário brasileiro. Mas essa é uma realidade latino-americana? A questão fica para o debate.

\section{Sexto ato}

\subsection{Considerações (provisoriamente) finais}

Refletir, sentir e escrever sobre a produção do conhecimento e a produção de identidades nos conduz a inúmeras camadas, que são reveladas ao longo da exploraçáo do tema. Há processos singulares e processos coletivos que se enredam durante a construção, compartilhamento e reprodução de saberes. Sáo processos complexos que não podem ser compartimentalizados porque foram tecidos juntos. Provisoriamente, entretanto, podemos apontar algumas consideraçóes finais.

Consideraçâo primeira: A experiência de se construir conhecimento é, por um lado, uma experiência solitária, vivida subjetiva e corporalmente. $\mathrm{O}$ ato de produzir saberes, novos ou complementares, traz as marcas de quem os produz e produz marcas em quem desenvolve essa atividade. Produz inquietação, apaixonamento; só satisfaz quando se consegue atingir um nível pleno de aprofundamento e enraizamento. Assim, é processo que requer tempo e dedicaçáo, difíceis de serem obtidos no assoberbamento cotidiano dos pesquisadores contemporâneos. Há questōes de gênero e de contexto que necessitam também ser debatidas no âmbito profissional de profisssóes como a Terapia Ocupacional.

Consideração segunda: Mesmo sendo o ato de produção do conhecimento uma atividade singular, ele é uma tarefa coletiva. Dialogamos com outros, com o que pensaram e escreveram, e nos apropriamos de suas ideias enquanto as reinterpretamos.
Nossos textos, quando publicados, ganham vida e deixam de ser nossos. Outros irão com eles dialogar, dar-lhes novos sentidos, possuí-los ou descartá-los. Quando se produz e reproduz conhecimentos, possibilita-se o surgimento de novas identificaçóes que podem ser valoradas e mantidas ou, simplesmente superadas.

Consideração terceira: A discussão sobre a questão da identidade parece necessária até nos debruçarmos sobre ela e constatarmos o que há nessa questão de fictício. É irreal falarmos de uma Terapia Ocupacional latino-americana, única e universal. Entretanto, compartilhamos várias identificaçôes em curso.

Quando produzimos saberes e práticas, produzimos identificaçóes, produzimos terapias ocupacionais. Dentre as identificações, constituídas na história latino-americana, temos tanto a valoração do individual e do universal como a valoração dos coletivos e dos contextos. Entretanto, tem sido a última que tem se destacado como a mais importante identificação em curso na Terapia Ocupacional latinoamericana pós-1990. A crítica à visão reducionista dos problemas sociais e a busca da transformação social têm um destaque importante. $\mathrm{O}$ compromisso ético-político dos profissionais, com vistas à promoção da participação social e à emancipação das pessoas e coletivos tem norteado estudos e práticas, ensino e pesquisa (GALHEIGO, 2011). Tais processos devem ser uma das razóes pelas quais muitos de nós, da América Latina e dos países do chamado Sul, não buscamos o conforto de modelos únicos, preditivos de Terapia Ocupacional. Acreditamos que a diversidade das identificaçóes é muito mais rica para a profissão do que a unicidade de uma identidade fixa. Assim, as metodologias que norteiam tais saberes e práticas e vêm sendo desenvolvidas nas últimas três décadas no âmbito da Terapia Ocupacional latino-americana podem ser identificadas com o que vem sendo compreendido como as epistemologias do Sul (SANTOS; MENESES, 2010).

Consideração quarta: A pressão por produtividade, que tem caracterizado o cotidiano universitário contemporâneo, é motivo de sofrimento e inquietaçáo. Ele corrompe e impede o pensar criativo e autônomo. Formata o pensamento e bloqueia o desenvolvimento de ideias que demandam tempo e estudo para florescerem.

Que identificações em cursos nós, latinoamericanos, temos em resposta às pressóes produtivistas e de desempenho que se preocupam táo pouco com a consolidaçáo e aprofundamento do conhecimento mas são movidas por contagens, medidas e ranqueamentos? Esse é um fenômeno da América Latina ou prioritariamente sentido no Brasil?

Consideraçâo quinta: Para finalizar, manifesto minha concordância com os argumentos de 
Boaventura de que a questão da identidade é semifictícia e seminecessária e de que a percepçáo de que se trata de uma necessidade fictícia faz parte do êxito da empreitada. Inspirada por suas ideias, concluo que as respostas encontradas na reflexão sobre Terapia Ocupacional, identidade e América Latina já eram em parte conhecidas.

\section{Ato final}

Terminada a apresentação, vem o debate. Consonância e dissenso. Uma participante pergunta por que consultar mecanismos de busca em inglês quando a discussão é latino-americana, e fica sem resposta a questão sobre como os terapeutas ocupacionais da América Latina podem superar a distância espacial, linguística e virtual.

O debate continua. Uma docente brasileira conta como a questáo do produtivismo tem começado a influenciar os estudantes de sua universidade em sua forma de pensar, gerando superficialidade em nome da produtividade. Há, na plateia, concordância de alguns brasileiros bem como divergência e surpreendimento de outros latino-americanos, o que recoloca a questão de se o impacto da demanda produtivista tem sido uma experiência prioritariamente nacional.

Essas e outras questốes apenas introduzem a discussão sobre os nexos e as identificaçôes em curso que acontecem na América Latina no que diz respeito às questôes da produçáo do conhecimento e da constituição das identidades profissionais. Seguiremos pensando, refletindo e nos surpreendendo. O que há nessa discussão que não se revela ao primeiro olhar? À divagação primeira? Que diálogos há a construir?

\section{Referências}

ClOUston, T. J.; WhitCOMBE, S. W. The professionalisation of occupational therapy: a continuing challenge. British Journal of Occupational Therapy, London, v. 71, n. 8, p. 314-320, 2008.

FURTADO, E. A. Conversando sobre identidade profissional. Revista de Terapia Ocupacional da USP, São Paulo, v. 10, n. 2-3, p. 46-48, 1999.

GALHEIGO, S. M. A transdisciplinaridade enquanto princípio e realidade das açôes de saúde. Revista de Terapia Ocupacional da USP, São Paulo, v. 10, n. 2-3, p. 49-54, 1999.
GALHEIGO, S. M. What needs to be done? Occupational therapy responsibilities and challenges regarding human rights. Australian Occupational Therapy Journal, Melbourne, v. 58, p. 60-66, 2011. PMid:21418227. http://dx.doi. org/10.1111/j.1440-1630.2011.00922.x

HOOGERDIJK, B.; RUNGE, U.; HAUGBOELLE, J. The adaptation process after traumatic brain injury an individual and ongoing occupational struggle to gain a new identity. Scandinavian Journal of Occupational Therapy, Oslo, v. 18, n. 2, p. 122-132, 2011. PMid:20384550. http://dx.doi.org/10.3109/11038121003645985

LIMA, E. M. A. Identidade e complexidade: composiçōes no campo da terapia ocupacional. Revista de Terapia Ocupacional da USP, v. 10, n. 2-3, p. 42-45, 1999.

MACHADO, M. C. Rumo à ciência da atividade humana. Revista de Terapia Ocupacional da USP, São Paulo, v. 2, n. 2-3, p. 60-65, 1991.

MacKEY, H. 'Do not ask me to remain the same': Foucault and the professional identities of occupational therapists. Australian Occupational Therapy Journal, Melbourne, v. 54, n. 2, p. 95-102, 2007. http://dx.doi. org/10.1111/j.1440-1630.2006.00609.x

MÂNGIA, E. F. Apontamentos sobre o campo da terapia ocupacional. Revista de Terapia Ocupacional da USP, São Paulo, v. 9, n. 1, p. 5-13, 1998.

METAXAS, V. A. Eleanor Clarke Slagle and Susan E. Tracy: Personal and professional identity and the development of occupational therapy in progressive era America. Nursing History Review, Philadelphia, v. 8, p. 39-70, 2000. PMid:10635685.

SANTOS, B. S. Pela mão de Alice: o social e o político na pós modernidade. São Paulo: Cortez Editora, 1999.

SANTOS, B. S.; MENESES, M. P. Epistemologias do Sul. São Paulo: Cortez Editora, 2010.

SMITH, L. D. et al. Belief in doing and knowledge in being mothers with arthritis. OTJR: Occupation, Participation and Health, Bethesda, v. 31, n. 1, p. 40-48, 2011. http://dx.doi.org/10.3928/15394492-20100222-01

TURNER, A. The Elizabeth Casson Memorial Lecture 2011: Occupational therapy - A profession in adolescence? British Journal of Occupational Therapy, London, v. 74, n. 7, p. 314-322, 2011. http://dx.doi.org/10.4276/0308 02211X13099513661036

WHITEFORD, G. E.; McALLISTER, L. Politics and complexity in intercultural fieldwork: the Vietnam experience. Australian Occupational Therapy Journal, Melbourne, v. 54, p. S74-S83, 2007. Supplement 1. http:// dx.doi.org/10.1111/j.1440-1630.2006.00607.x

\section{Notas}

${ }^{1}$ Artigo apresentado na Mesa redonda "As questôes da produçâo do conhecimento e da constituição das identidades na América Latina” no XII Congresso Brasileiro e IX Latino-Americano de Terapia Ocupacional, realizado em São Paulo, de 11 a 14 de outubro de 2011 . 